\title{
ESTUDO DO POTENCIAL ANTINOCICEPTIVO DE EXTRATOS DA FOLHA E DO CERNE DA GUATTERIA POGONOPUS
}

\author{
$\underline{\text { Joice Souza de Sena }}{ }^{1}$; Flávia de Oliveira Lima $^{2}$ e Emmanoel Vilaça Costa ${ }^{3}$. \\ 1. Bolsista PROBIC, Graduando em Farmácia, Universidade Estadual de Feira de Santana, e-mail: \\ joicefarmacia@hotmail.com \\ 2. Orientador, Departamento de Saúde, Universidade Estadual de Feira de Santana, e-mail: \\ flavia_lima2000@yahoo.com.br \\ 3. Colaborador, Departamento de Química, Universidade Federal do Amazonas, \\ e-mail: emmanoelvc@gmail.com
}

PALAVRAS-CHAVE: Antinocicepção, Plantas, Guatteria pogonopus.

\section{INTRODUÇÃO}

O gênero Guatteria (Ruiz \& Pav.) é o maior da família Annonaceae com aproximadamente 290 espéicies conhecidas. Estudos de algumas espécies de Guatteria têm revelado algumas propriedades farmacológicas: como antioxidante, antimicrobiana, anti-malária, leishmanicida, insecticida, e efeitos citotóxicos (Costa et al,2013).

Guatteria pogonopus Mart. é uma espécie amplamente encontrada no semiárido baiano, apresentando status de conservação de Baixo Risco com fácil reconhecimento pelas folhas de grandes dimensões e pelo curto pedicelo da flor e do fruto. Existem poucos estudos sobre esta espécie, dentre eles, o estudo fitoquímico que isolou alcalóides presentes nas folhas e cascas do caule da Guatteria pogonopus (Santos, 2015). Assim, o objetivo deste trabalho é avaliar a ação antinociceptiva do extrato metanólico das folhas e do cerne da Guatteria pogonopus Mart.

\section{MATERIAL E MÉTODOS}

\section{Animais Experimentais}

Os experimentos foram realizados com camundongos machos da linhagem Swiss Webster (20-30g) criados no biotério da Universidade Estadual de Feira de Santana. Os animais foram alocados em caixas apropriadas e mantidos nas dependências do biotério, sob temperatura de $22-25^{\circ} \mathrm{C}$ e ciclos claro-escuro de 12 horas, com livre acesso a ração e água. Todos os experimentos foram realizados de acordo com protocolo da IASP para uso de animais de laboratório (Zimmermann,1983).

\section{Modelo de contorções abdominais induzidas pelo ácido acético}

Os animais foram tratados por via oral com Extrato Hexânico ou Metanólico das folhas de Guateria Pogonopus ou com Extrato Metanólico do cerne de Guateria Pogonopus ou veículo (grupo de controle negativo) antes da administração intraperitoneal de ácido acético $(0,8 \% \mathrm{v} / \mathrm{v}, 10 \mathrm{ml} / \mathrm{kg})$. A administração de morfina subcutânea $(5 \mathrm{mg} / \mathrm{kg})$ foi utilizada como fármaco de referência, 40 minutos antes do estímulo nociceptivo. A resposta de contorção consistiu numa extensão do músculo abdominal juntamente com um alongamento dos membros posteriores (COLLIER et al., 
1968). A intensidade de nocicepção foi quantificada em número de contorções abdominais durante os 30 minutos seguintes à injeção de estímulo.

\section{Analise Estatística}

Os resultados obtidos foram analisados estatisticamente e representados como média \pm E.P.M de seis animais por grupo, sendo os grupos experimentais comparados pelo teste one-way ANOVA, seguido do teste Bonferroni. O nível de significância foi de $\mathrm{p}<0,05$.

\section{RESULTADOS E/OU DISCUSSÃO}

No teste realizado, os camundongos tratados com $400 \mathrm{mg} / \mathrm{kg}$ do Extrato Hexânico das folhas de Guateria Pogonopus(EHGP) apresentou uma média de contorções de 41.33 enquanto o grupo controle negativo houve uma média de 48.67(p > 0,05). Portanto, nota-se que não houve inibição significante do número de contorções dos camundongos pré-tratados com EHFGP. Morfina $(5 \mathrm{mg} / \mathrm{kg} / \mathrm{s.c}$.), um analgésico opióide utilizado como referência, produziu inibição significante do número de contorções ( $\mathrm{p}<0,0001)$ (Figura 1).

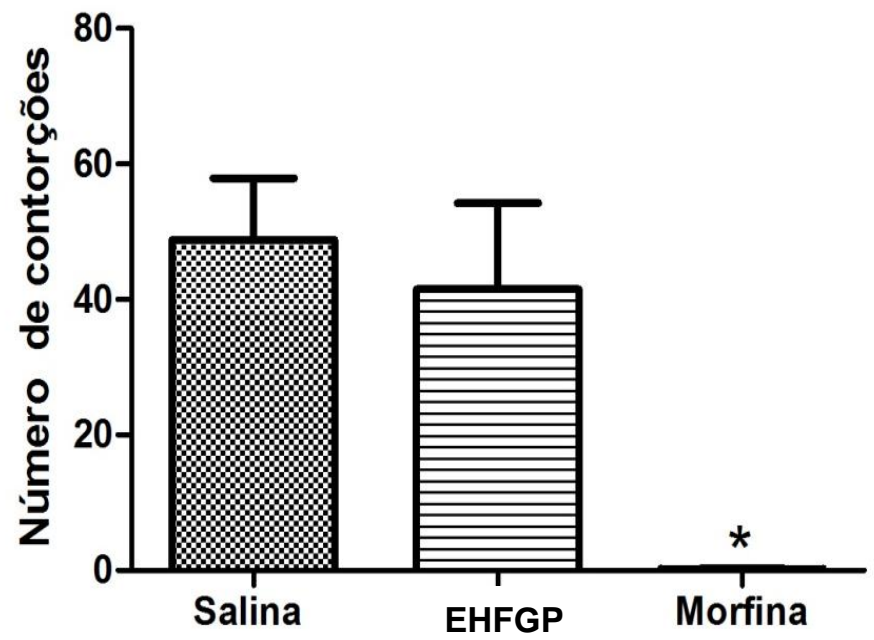

Fig. 01- Os camundongos foram tratados com o Extrato Hexânico das Folhas da Guatteria Pogonopus (EHGP; 400mg/kg) ou salina + TWEEN à 1,78\% (grupo controle negativo) por via intraperitoneal $1 \mathrm{~h}$ antes do ácido acético a $0,8 \%$. Morfina (Mor; $5 \mathrm{mg} / \mathrm{kg}$, s.c., grupo controle positivo) foi utilizada como fármaco padrão, sendo administrados por via subcutânea 40 minutos antes do ácido acético. Os dados estão expressos como média \pm E.P.M.; $\mathrm{n}=6$ camundongos por grupo. * significância estatística em relação ao grupo controle negativo $(\mathrm{p}<0,0001)$, como determinado por ANOVA seguido pelo teste de Bonferroni.

Posteriormente, foi avaliado o efeito do tratamento com o extrato metanólico das folhas de Guatteria Pogonopus (EMFGP). O tratamento com 400mg/kg do EHGP 1 hora antes da injeção i.p. do ácido acético resultou numa média de contorções de 49.50, enquanto o grupo controle negativo apresentou uma média de 57.67(p > 0,05). Apesar de uma aparente redução na média das contorções dos camundongos tratados com o extrato em relação o controle negativo, não houve uma redução significante. Morfina 
(5mg/kg/s.c.), um analgésico opióide utilizado como referência, produziu inibição significante do número de contorções $(\mathrm{p}<0,0001)$ (Figura 2).

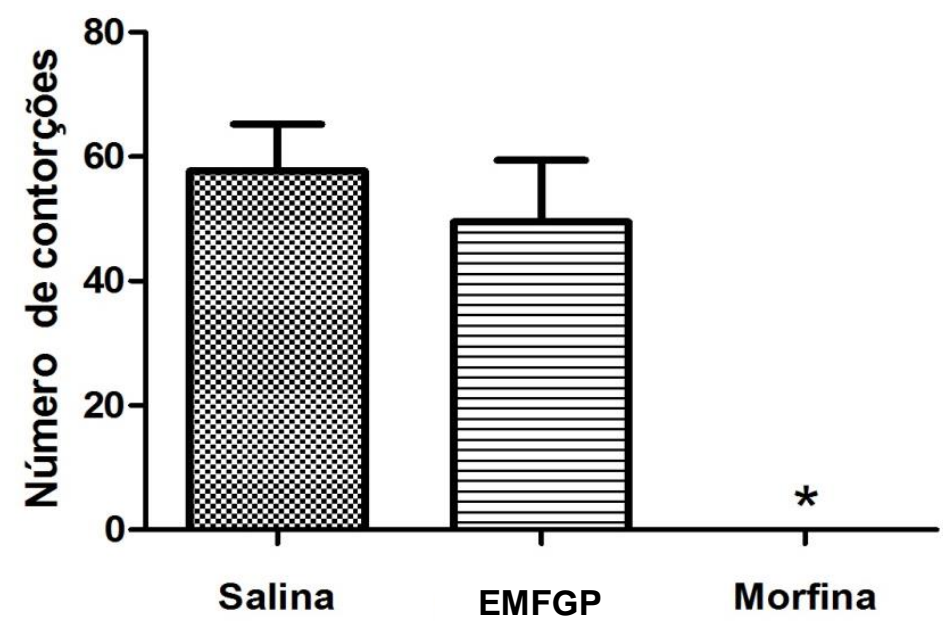

Fig. 02- Os camundongos foram tratados com o Extrato Metanólico das folhas de Guatteria Pogonopus (EMFGP; 400mg/kg) ou salina + DMSO à 5\% (grupo controle negativo) por via oral 1 hora antes do ácido acético a $0,8 \%$. Morfina (Mor; $5 \mathrm{mg} / \mathrm{kg}$, s.c., grupo controle positivo) foi utilizada como fármaco padrão, sendo administrada por via subcutânea 40 minutos antes do estímulo nociceptivo. Os dados estão expressos como média \pm E.P.M.; $\mathrm{n}=6$ como determinado por ANOVA seguido pelo teste de Bonferroni. * significância estatística em relação ao grupo controle negativo ( $\mathrm{p}<0,0001)$, como determinado por ANOVA seguido pelo teste de Bonferroni.

O último extrato testado foi o extrato metanólico do cerne da Guatteria Pogonopus (EMCGP). O grupo tratado com 400mg/kg do EMCGP apresentou uma média de contorções de 43,17, enquanto o grupo não tratado apresentou uma média de contorções de 59,17 ( $\mathrm{p}>$ 0,05). Apesar de uma aparente redução na média das contorções dos camundongos tratados com o EMCGP em relação ao grupo controle negativo, não houve uma redução significante do numero de contorções abdominais após o tratamento com EMCGP. Morfina $(5 \mathrm{mg} / \mathrm{kg} / \mathrm{s.c}$.), um analgésico opióide utilizado como referência, produziu inibição significante do número de contorções $(\mathrm{p}<0,0001)$ (figura 3).

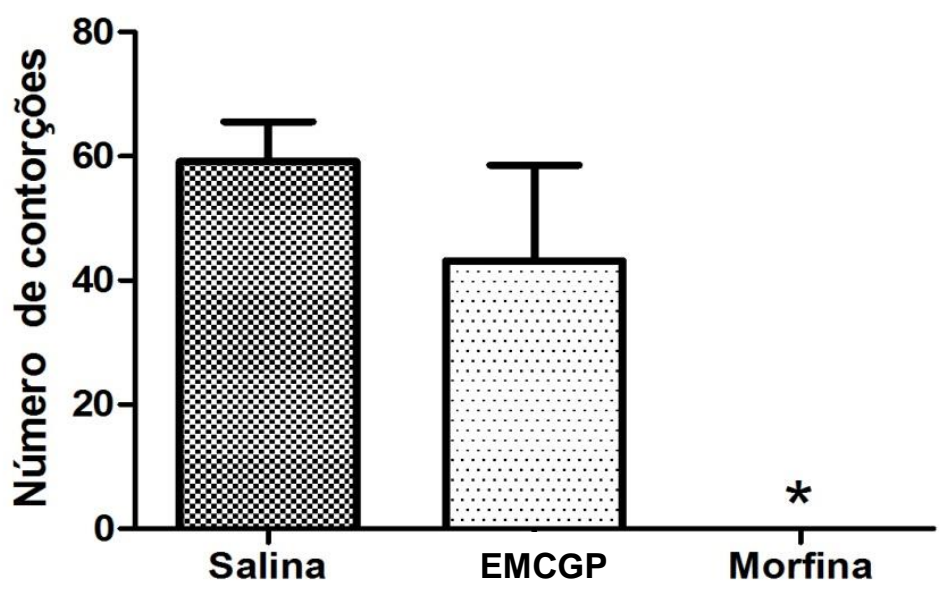


Fig. 03- Os camundongos foram tratados com a Extrato Metanólico do Cerne de Guatteria Pogonopus (EMCGP; 400mg/kg) ou salina + DMSO à 5\% (grupo controle negativo) por via oral 30 minutos antes do ácido acético a 0,8\%. Morfina (Mor; $5 \mathrm{mg} / \mathrm{kg}$, s.c., grupo controle positivo) foi utilizada como fármaco padrão, sendo administrada por via subcutânea 40 minutos antes do estímulo nociceptivo. Os dados estão expressos como média \pm E.P.M.; $\mathrm{n}=6$ como determinado por ANOVA seguido pelo teste de Bonferroni. * significância estatística em relação ao grupo controle negativo $(\mathrm{p}<0,0001)$, como determinado por ANOVA seguido pelo teste de Bonferroni.

Apesar de considerado um modelo simples, o modelo do ácido acético apresenta boa sensibilidade na descoberta de substâncias com potencial analgésico e antiinflamatório (BLUMBERG et al., 1965). Como esse teste possui alta sensibilidade (VIDYALAKSHMI et al., 2010), não houve necessidade da continuação dos experimentos com os extratos da folha e cerne da Guatteria Pogonopus.

\section{CONSIDERAÇÕES FINAIS}

De acordo com os resultados obtidos, os extratos hexânico e metanólico das folhas da Guatteria Pogonopus, bem como o extrato metanólico do cerne da Guatteria Pogonopus na dose testada não demonstraram inibição das contorções abdominais induzidas pelo ácido acético em camundongos. Como o modelo de contorção abdominal induzida pelo ácido acético possui alta sensibilidade e os extratos não foram capazes de inibir o número de contorções abdominais induzidas pelo ácido acético, não houve necessidade da continuidade dos outros experimentos propostos no plano de trabalho.

\section{REFERÊNCIAS}

KOSTER R, ANDERSON M, DE DEBEER EJ 1959. Acetic acid for analgesic screening. Fed Proc 18: 412-418.

WHITTLE BA. Release of a kinin by intraperitoneal injection of chemical agents in mice. J Neuropharmacol 3: 369 - 378, 1964.

ZIMMERMANN, M. Ethical guidelines for investigations of experimental pain in conscious animals. Pain, Vol.16, p.109-110, 1983.

BLUMBERG, $\mathrm{H}$. et al. Used of the writhing test for evaluating analgesic activit of narcotic antagonists. Proc. Soc. Exp. Biol. Med., v. 118, 1965, p. 763-766

QUEIROZ, A. C. et al. The antinociceptive and antiinflammatory activities of Piptadenia stipulacea Benth. (Fabaceae). Journal of Ethnopharmacology, v. 128, n. 2, p. 377-83, 2010.

VIDYALAKSHMI, K. et al. Antinociceptive effect of certain dihydroxy flavones in mice. Pharmacology, Biochemistry and Behavior, v. 96, p. 1-6, 2010. COSTA, E. V.; CRUZ, P. E.; PINHEIRO, M. L.; MARQUES, F. A.; RUIZ, A. L. T. G.; MARCHETTI, G. M.; CARVALHO, J. E.; BARISON, A.; MAIA, B. H. L. N. S. Aporphine and Tetrahydroprotoberberine Alkaloids from the Leaves of Guatteria 
friesiana (Annonaceae) and their Cytotoxic Activities. J. Braz. Chem. Soc., Vol. 24, p. 788-796, 2013.

SANTOS, M. F. C. Estudo fitoquímico e investigação da atividade citotóxica das folhas e cascas do caule de guatteria pogonopus (Annonaceae). Dissertação (Mestrado em Química). Universidade Federal de Sergipe. São Cristovão, 2015 